\title{
Traumatic abdominal wall hernia with Morel-Lavallée lesion: a case report
}

\author{
Yoonjung Heo, Dong Hun Kim \\ Department of Trauma Surgery, Trauma Center, Dankook University Hospital, Cheonan, \\ Korea
}

Received May 30, 2020

Revised June 5, 2020

Accepted June 11, 2020

Correspondence to

Dong Hun Kim

Department of Trauma Surgery, Trauma

Center, Dankook University Hospital,

201 Manghyang-ro, Dongnam-gu,

Cheonan 31116, Korea

Tel: +82-41-550-7119

Fax: +82-41-550-0039

E-mail: saint7331@gmail.com

\begin{abstract}
The prevalence of traumatic abdominal wall hernias (TAWHs) after blunt abdominal trauma is approximately $1 \%$. When TAWHs are accompanied by a Morel-Lavallée lesion (MLL), a closed traumatic injury involving soft tissue degloving, affected patients become susceptible to severe soft tissue infection, which necessitates challenging treatments. However, no guidelines regarding an optimal management strategy have been published. Here we describe the successful treatment of a TAWH accompanied by an MLL in the anterior lower abdomen of a 66-year-old woman who sustained a seatbelt injury after a traffic accident while driving.
\end{abstract}

Key Words: Wounds, Nonpenetrating, Soft tissue infections, Hernia, Abdomen

\section{Introduction}

Traumatic abdominal wall hernias (TAWHs) most commonly occur following motor vehicle collisions (1). In high-energy trauma, the incidence of intra-abdominal injuries associated with TAWHs that require surgical repair was reported to reach up to $100 \%$ (2). Accompanying bowel incarceration occurs in $25 \%$ of all TAWH cases (3). However, TAWHs associated with a Morel-Lavallée lesion (MLL) caused by seatbelt injury have rarely been reported. MLLs are closed traumatic injuries involving separation of the soft tissue from the underlying fascia. Herein, we describe the successful surgical management of an MLL in a patient with septic shock following primary repair of TAWH.

\section{Case presentation}

A 66-year-old woman suffered a seatbelt injury in a traffic accident while driving. She had undergone cesarean section via a low midline incision 20 years earlier. Upon admission by way of a local hospital, her blood pressure was $93 / 54 \mathrm{mmHg}$, pulse rate was 117 beats/min, respiratory rate was 26 breaths/min, and body temperature was $35^{\circ} \mathrm{C}$. She received transfusion of four units of packed red blood cells. On physical examination, she was found to have abdominal distension with signs of diffuse peritoneal irritation and a horizontal bruise (the seatbelt sign) on the lower abdomen (Fig. 1). Abdominal computed tomography revealed small bowel herniation through the lower abdominal wall, extravasation from mesenteric vessels, intra-abdominal free air, fluid collection in the anterior abdominal wall adjacent to the herniated bowel, and a stable aortic dissection just above the aortic bifur-

(C)This is an Open Access article distributed under the terms of the Creative Commons Attribution Non-Commercial License (http://creativecommons.org/licenses/by-nc/4.0) which permits unrestricted noncommercial use, distribution, and reproduction in any medium, provided the original work is properly cited.

Copyright (c) 2020 Korean Association for Research, Procedures and Education on Trauma. All rights reserved. 
cation (Fig. 2). The patient's injury severity score was 27. She underwent emergency laparotomy, which revealed massive small bowel herniation as large as the size of the abdominal wall defect through the cesarean midline incision, multiple perforations of the small bowel with spillage of bowel contents, and mesenteric lacerations with active bleeding (Video 1). The herniation extended transversely in both directions from the low midline. Simultaneously, an MLL was found tunneled into the anterior aspect of the anterior sheath of the abdominal wall, and the lesion conformed to the seatbelt injury at the lower abdomen. We performed primary repair of the small bowel and mesentery and hernioplasty for TAWH. Septic shock developed immediately thereafter, with aggravation of skin ischemia along the seatbelt sign (Fig. $3 \mathrm{~A}$ and $3 \mathrm{~B}$ ). Wide excision and debridement of the skin and subcutaneous tissue were performed on hospital day (HD) 4 , and then negative-pressure wound therapy (NPWT) with vacuum

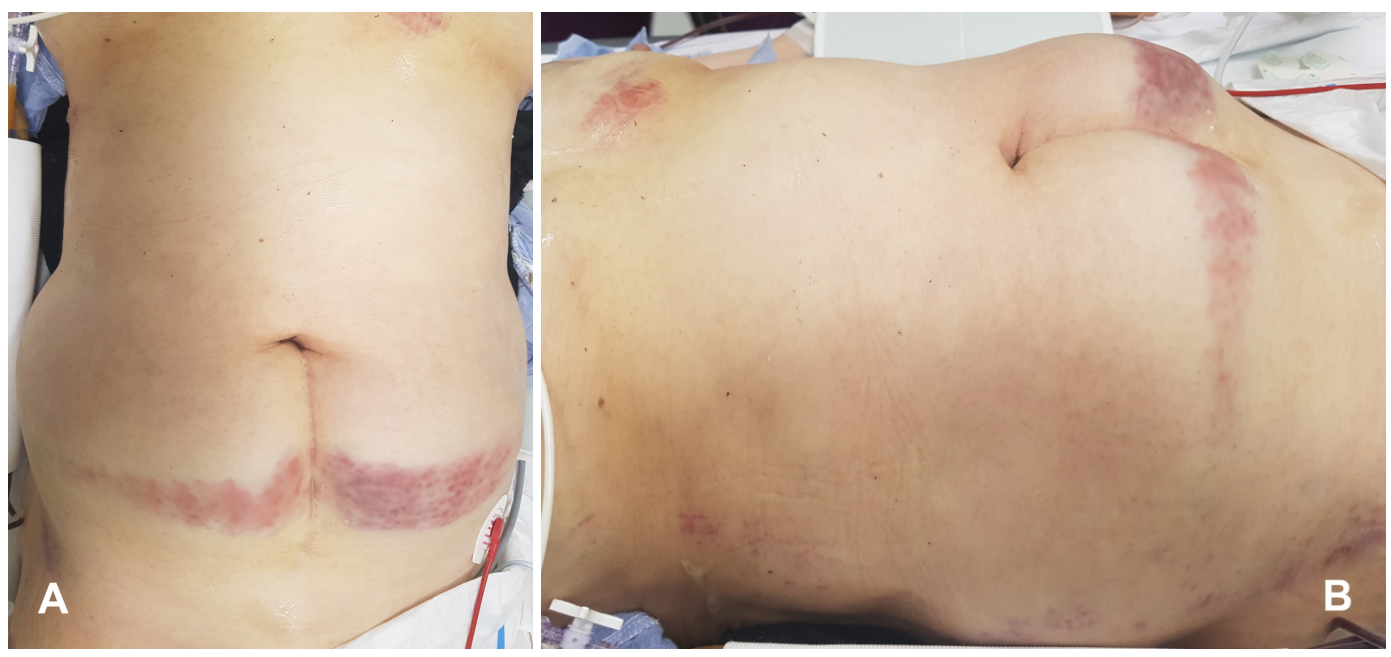

Fig. 1. External photographs reveal abdominal bulging on both sides of the cesarean scar and horizontal bruises on the lower abdomen (A and $\mathrm{B})$.
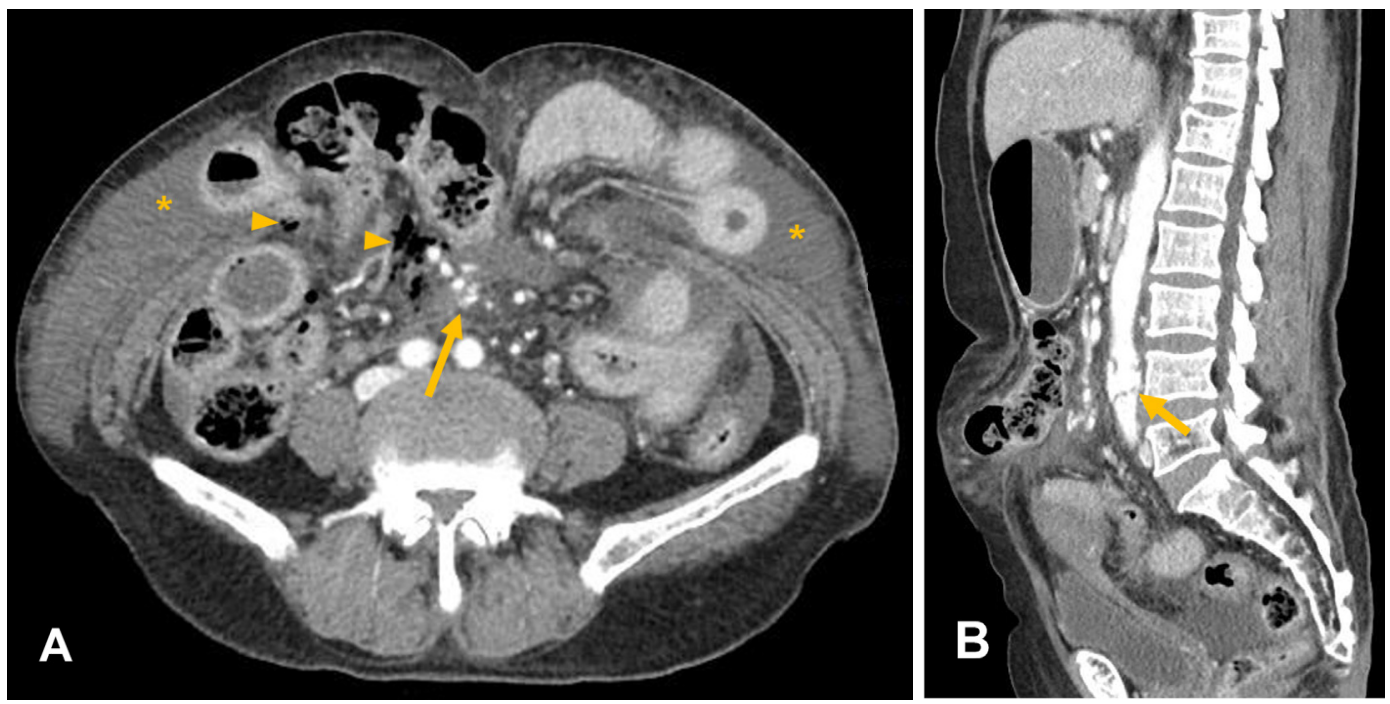

Fig. 2. Abdominal computed tomography scans show (A) small bowel herniation through the abdominal wall with intraperitoneal free air (arrow heads), free fluid (asterisks) in the anterior abdominal wall, and extravasation from mesenteric vessels (arrow) and (B) an abdominal aortic dissection just above the aortic bifurcation (arrow). 
was applied subsequently (Fig. 3C). Her serum C-reactive protein and procalcitonin levels decreased from $31.51 \mathrm{mg} /$ $\mathrm{dL}$ and $>100 \mathrm{ng} / \mathrm{mL}$, respectively, on HD 4 to $21.62 \mathrm{mg} /$ $\mathrm{dL}$ and $35.15 \mathrm{ng} / \mathrm{mL}$, respectively, on HD 6, and the sepsis subsided gradually. The excised wound was approximated piecemeal with NPWT, and by HD 81, it had completely healed without skin grafting, since the patient was obese and had redundant skin and subcutaneous tissue (Fig. 4). Unfortunately, she died of aspiration pneumonia on HD 125.
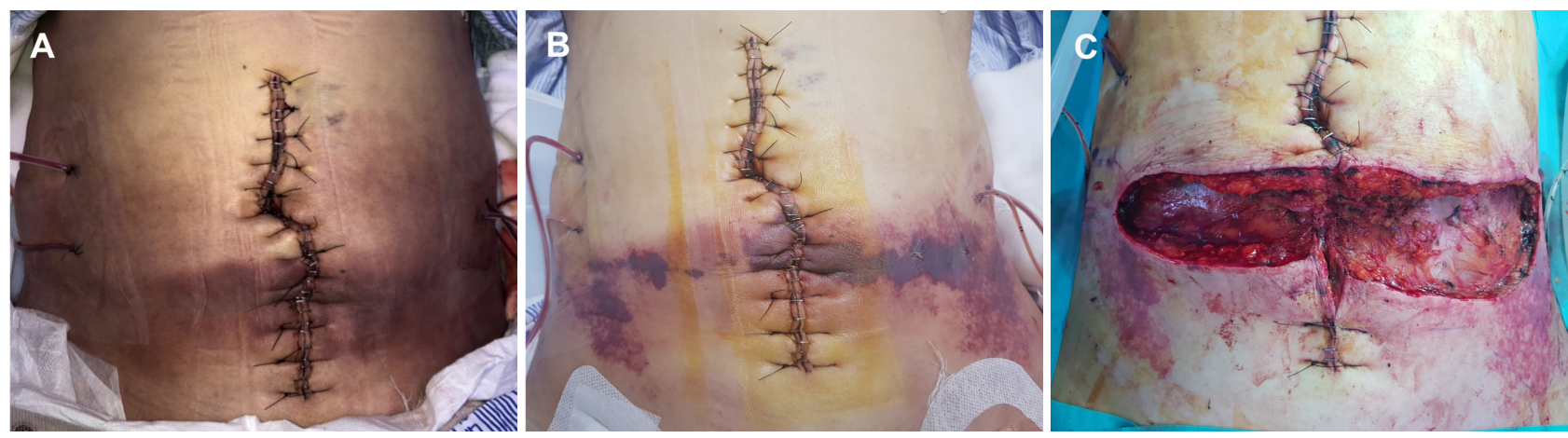

Fig. 3. External photographs show the Morel-Lavallée lesion on the lower abdomen. (A) Inflammatory changes such as erythema and swelling were noted on hospital day 3. (B) Ischemic change of skin with progression of surrounding erythema was observed on hospital day 4. (C) The appearance of the wound after wide excision of ischemic skin and subcutaneous tissue removal is shown.
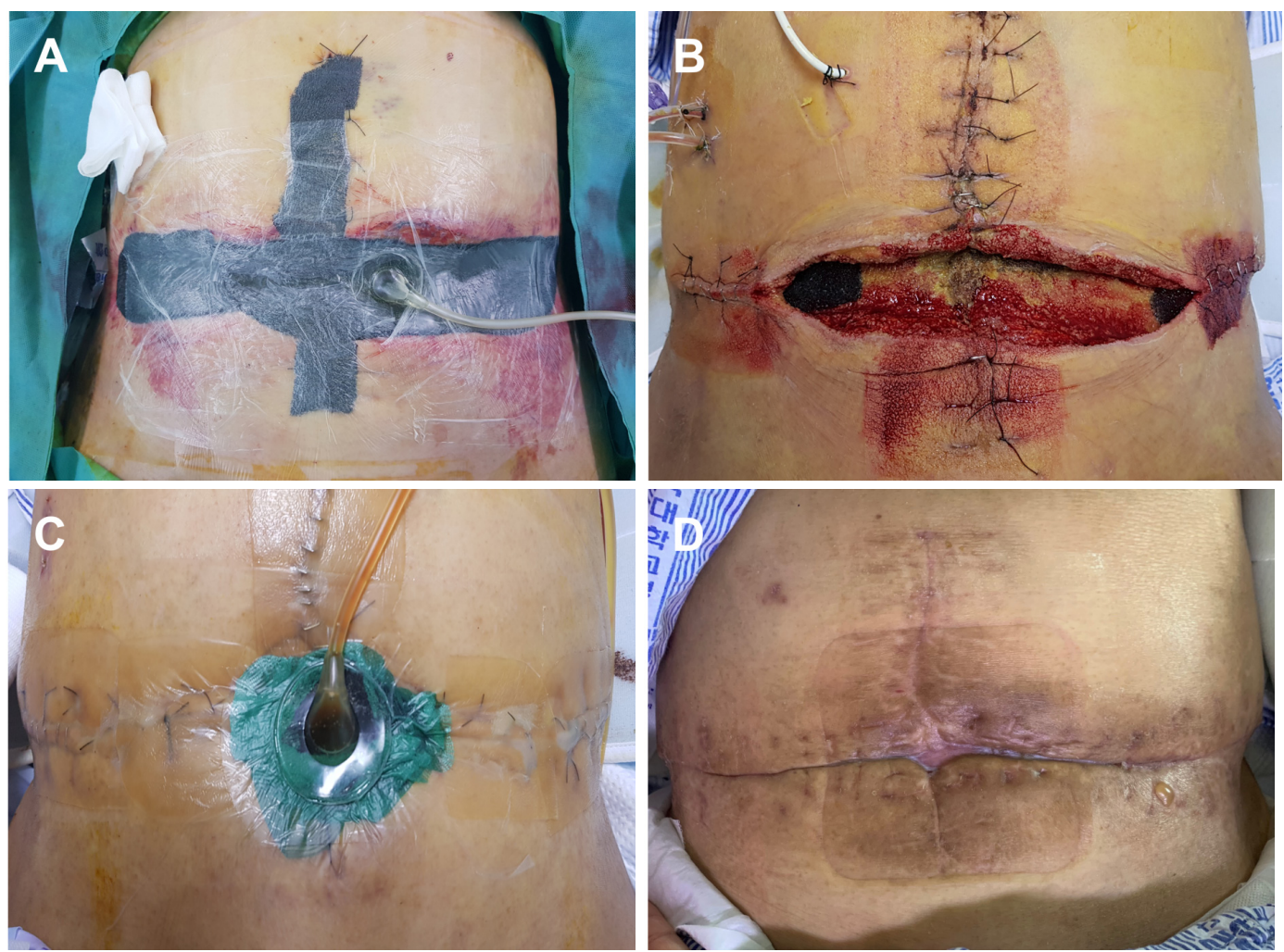

Fig. 4. External photographs of the wide excision wound. (A) Negative-pressure wound therapy was applied with vacuum dressing. (B) Wound approximation was started from both sides on hospital day 18. (C) The wound was $80 \%$ approximated, except for the central portion, on hospital day 31. (D) The wound healed completely by hospital day 81. 


\section{Discussion}

Three clinical points must be considered in the management of patients with a TAWH. The first point is to determine whether exploratory laparotomy is necessary. Currently, there are no consensus guidelines regarding the indications; however, surgery is warranted when patients have symptomatic injuries of other organs, visceral incarceration, or strangulation (1). The second point concerns the ideal timing of hernia repair. Repair should be delayed in unstable patients (4). The last point concerns how to repair the hernia: whether to perform tissue or mesh repairs. Surgeons should focus on the increased risk of infection by using a mesh in patients with concomitant intra- or extra-abdominal lesions (4). In our patient, operative intervention was urgent, and primary repair was performed because panperitonitis developed.

TAHWs located in the anterior abdomen are more likely to require surgical repair than those in other locations because they are frequently accompanied by direct injuries of the mesentery or bowel (1). Such injuries, defined as seatbelt syndrome, represent damage caused by shearing forces against the underlying organs in the lower abdomen that are caused by restraint and rapid deceleration (5). This syndrome commonly involves TAWHs but rarely MLLs. Patients with MLLs are susceptible to severe soft tissue infection (6), which can even lead to septic shock when accompanied by bowel perforations, as in our patient. Thus, treating MLLs accompanied by infection is challenging. Early surgical debridement of an infected MLL could increase the chances of survival $(6,7)$.

\section{Conflict of interest}

No potential conflict of interest relevant to this article was reported.

\section{Supplementary material}

Supplementary data including one video can be found with this article online at www.traumaimpro.org.

Video 1. Emergency laparotomy: primary repair of the small bowel and mesentery, abdominal wall repair, and exploration of the Morel-Lavallée lesion sustained in a seatbelt injury.

\section{References}

1. Coleman JJ, Fitz EK, Zarzaur BL, Steenburg SD, Brewer BL, Reed RL, et al. Traumatic abdominal wall hernias: Location matters. J Trauma Acute Care Surg. 2016;80(3):390-7.

2. Lane CT, Cohen AJ, Cinat ME. Management of traumatic abdominal wall hernia. Am Surg. 2003;69(1):736.

3. Esposito TJ, Fedorak I. Traumatic lumbar hernia: case report and literature review. J Trauma. 1994;37(1):1236.

4. Hamidian Jahromi A, Skweres J, Sangster G, Johnson L, Samra N. What we know about management of traumatic abdominal wall hernia: review of the literature and case report. Int Surg. 2015;100(2):233-9.

5. Biswas S, Adileh M, Almogy G, Bala M. Abdominal injury patterns in patients with seatbelt signs requiring laparotomy. J Emerg Trauma Shock. 2014; 7(4):295-300.

6. Scolaro JA, Chao T, Zamorano DP. The Morel-Lavallée lesion: diagnosis and management. J Am Acad Orthop Surg. 2016;24(10):667-72.

7. Shaban Y, Elkbuli A, Ovakimyan V, Hai S, McKenney M, Boneva D. The first reported case of Morel-Lavallée lesion and traumatic abdominal wall hernia: A case report and review of the literature. Am J Case Rep. 2019;20:1492-6. 